\title{
Localized mixed-valence and redox activity within a triazole-bridged dinucleating ligand upon coordination to palladium
}

Article

Accepted Version

Broere, D. L. J., Plessius, R., Tory, J., Demeshko, S., de Bruin, B., Siegler, M. A., Hartl, F. and van der Vlugt, J. I. (2016) Localized mixed-valence and redox activity within a triazolebridged dinucleating ligand upon coordination to palladium. Chemistry- A European Journal, 22 (39). pp. 13965-13975. ISSN 1521-3765 doi: https://doi.org/10.1002/chem.201601900 Available at https://centaur.reading.ac.uk/66561/

It is advisable to refer to the publisher's version if you intend to cite from the work. See Guidance on citing.

To link to this article DOI: http://dx.doi.org/10.1002/chem.201601900

Publisher: Wiley

All outputs in CentAUR are protected by Intellectual Property Rights law, including copyright law. Copyright and IPR is retained by the creators or other copyright holders. Terms and conditions for use of this material are defined in the End User Agreement. 


\section{CentAUR}

Central Archive at the University of Reading

Reading's research outputs online 


\title{
Localized Mixed Valence and Redox-Activity within a Triazole- Bridged Dinucleating Ligand upon Coordination to Palladium
}

\author{
Daniël L. J. Broere,${ }^{[a]}$ Raoul Plessius, ${ }^{[a]}$ Joanne Tory, ${ }^{[b]}$ Serhiy Demeshko, ${ }^{[c]}$ Bas de Bruin, ${ }^{[a]}$ Maxime A. \\ Siegler, ${ }^{[\mathrm{d}]}$ Frantisek Hart ${ }^{[\mathrm{b}]}$ and Jarl Ivar van der Vlugt ${ }^{*[\mathrm{a}]}$
}

\begin{abstract}
The new dinucleating redox-active ligand $\left(\mathrm{L}^{\mathrm{H}}{ }^{4}\right)$, bearing two redox-active NNO-binding pockets linked by a 1,2,3-triazole unit, is synthetically readily accessible. Coordination to two equivalents of $\mathrm{Pd}(\mathrm{II})$ resulted in the formation of paramagnetic $(S=1 / 2)$ dinuclear $\mathrm{Pd}$ complexes with a $\mathrm{K}^{2}-N, N^{\prime}$ bridging triazole and a single bridging chlorido or azido ligand. A combined spectroscopic, spectroelectrochemical and computational study confirmed RobinDay Class II mixed valence within the redox-active ligand, with little influence of the secondary bridging anionic ligand. Intervalence charge transfer was observed between the two ligand binding pockets. Selective one-electron oxidation allowed for isolation of the corresponding cationic ligand-based diradical species. SQUID measurements of these compounds revealed weak antiferromagnetic spin coupling between the two ligand-centered radicals and an overall singlet ground state in the solid state, which is supported by DFT calculations. The rigid and conjugated dinucleating redox-active ligand framework thus allows for efficient electronic communication between the two binding pockets.
\end{abstract}

\section{Introduction}

Mixed valence compounds are defined as containing a redoxactive fragment that is present in more than one (formal) oxidation state. ${ }^{[1]}$ Depending on the extent of electronic communication between the two sites, mixed valence compounds have been divided into three classes according to the Robin-Day classification..$^{[2]}$ Class I compounds contain distinct sites with localized specific valences that have no (measurable) interaction. Intermediate Class II species exhibit a measurable low barrier for electron transfer and some degree of electronic communication between the two localized specific

[a] D.L.J. Broere, R. Plessius, Prof.Dr. B. de Bruin, Dr.ir. J.I. van der Vlugt*

Homogeneous, Bioinspired and Supramolecular Catalysis, van 't Hoff Institute for Molecular Sciences

University of Amsterdam

Science Park 904, 1098 XH Amsterdam, the Netherlands E-mail: j.i.vandervlugt@uva.nl

[b] Dr. J. Tory, Prof.Dr. F. Hartl

Department of Chemistry, University of Reading, Whiteknights, Reading RG6 6AD, United Kingdom

[c] Dr. S. Demeshko

Institut für Anorganische Chemie, Georg-August-Universität Göttingen, Tammanstrasse 4, 37077 Göttingen, Germany

[d] Dr. M.A. Siegler

Department of Chemistry, John Hopkins University, 3400 N. Charles St., Baltimore, MD, 21218, USA

Supporting information for this article is given via a link at the end of the document. valence sites. In Class III compounds, strong electronic interaction due to full delocalization over the entire system prevents the spectroscopic observation of distinguishable redoxstates. Prussian blue, the first modern synthetic pigment, ${ }^{[3]}$ and the Ru-based Creutz-Taube complex are textbook examples of mixed valence compound. ${ }^{[4]}$ The targeted design of mixed valence complexes was initiated in the $1970 \mathrm{~s},{ }^{[5]}$ but because of the difficulties in directly measuring intramolecular electron transfer processes, the synthesis and characterization of welldefined mixed valence species continues to draw much attention, as these enable the measurement of rate constants and activation barriers for intramolecular electron transfer by analysis of the IVCT band. ${ }^{\left[{ }^{6]}\right.}$ For symmetric mixed valence compounds these absorption bands are typically found in the low-energy visible or near-infrared (NIR) region.

To further aid the understanding of basic electron-transfer in complex biophysical processes and electronic devices (e.g. OLEDs) and to validate spectroscopic methods, there is also great interest in the design and synthesis of purely organic mixed valence compounds as model systems. ${ }^{[7]}$ Fundamental research towards NIR absorbing materials is driven by several practical applications in communication, bio-imaging, sensing, and advanced optoelectronics. ${ }^{[8]}$ The deep penetration in human tissue of NIR radiation has resulted in a great interest towards electrochromic NIR dyes for cancer targeting and imaging. ${ }^{[9]}$ Metal complexes containing (imino)semiquinonato ligands often show strong NIR intraligand charge transfer (CT) bands. ${ }^{[10]}$ In combination with the ability to readily undergo ligand oxidation state changes upon reduction or oxidation, such complexes are potentially useful for switchable NIR filters.

Besides the emerging research direction to use redox-active ligand systems as electron reservoirs for bond activation and catalysis $^{[11][12]}$ these organic fragments are also frequently employed in the synthesis of mixed valent systems. ${ }^{[13]}$ Two main strategies involving the use of redox-active ligands have been pursued to date (Figure 1): i) mononuclear systems bearing separate redox-active ligands or tethered redox-active pockets within the same ligand amenable to controlled and independent redox-switching ${ }^{[14]}$ and ii) dinuclear complexes with redox-active metal centers and a redox-active organic bridging unit. When this dinucleating fragment itself exhibits redox-activity, the delocalized $\pi$-system supports electronic communication between the two metal-centered redox-sites. ${ }^{[15]}$ In the context of developing mixed valent compounds based on organic redoxactive sites, examples exist of metal complexes, bearing two or three identical redox-active ligand fragments, that are connected via bridging linkers attached to these ligands. ${ }^{[16]}$ In this design, which appears limited to homoleptic coordination spheres around the metal centers, there is communication within one center and between the two binding pockets. 


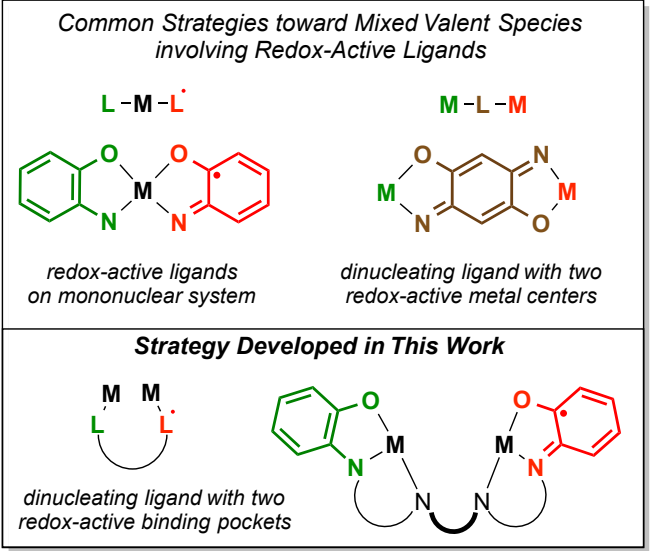

Figure 1. Schematic illustration of current-day strategies to invoke mixed valency involving redox-active ligand coordination chemistry (top) and new strategy disclosed herein (bottom).

A hitherto underexplored and potentially more versatile strategy to invoke mixed valency would target dinucleating ligands containing a suitable linker and two redox-active binding pockets amenable to hosting two (redox-inert) metal centers. This would provide coordination-induced stabilization of the redox events occurring within the organic ligand fragments, allow tunable electronic communication (by adjusting the linker) and enable chemistry between the two metal centers, i.e. at the bridgehead position of these heteroleptic coordination compounds.

We previously reported on the synthesis and properties of dinuclear ' $\mathrm{Pd}(\mathrm{II})$ complexes bearing either one redox-active phosphine appended $\mathrm{PNO}^{[17]}$ or pyridine appended $\mathrm{NNO}^{[18]}$ ligand per $\mathrm{Pd}$, with various bridging co-ligands. ${ }^{[19]}$ The intramolecular spin-exchange coupling $(J)^{[20]}$ and $d^{8}-d^{8}$ interaction between both $\mathrm{Pd}(\mathrm{II})$ centers were strongly influenced by the (pseudo)halide bridge (Figure 2). However, these complexes were unstable to exogenous ligands or strongly coordinating solvents, which prevented detailed investigation into intramolecular electron transfer phenomena. Hence, we sought to construct an organic framework containing two individually addressable redox-active compartments. We therefore set out to prepare a ligand scaffold containing two oaminophenol-derived binding pockets and a nitrogen-containing linker to provide an inert alternative to the labile dinuclear $\left[\left\{\mathrm{Pd}\left(\mathrm{NNO}^{\mathrm{ISQ}}\right)\right\}_{2}(\mu-\mathrm{X})\right]^{+} \quad$ complexes, whilst still enforcing a tridentate NNO binding mode for each metal center. This would in turn allow for the study of ligand-based mixed valence dinuclear complexes, intervalence charge transfer and the characteristics of organic diradical species.

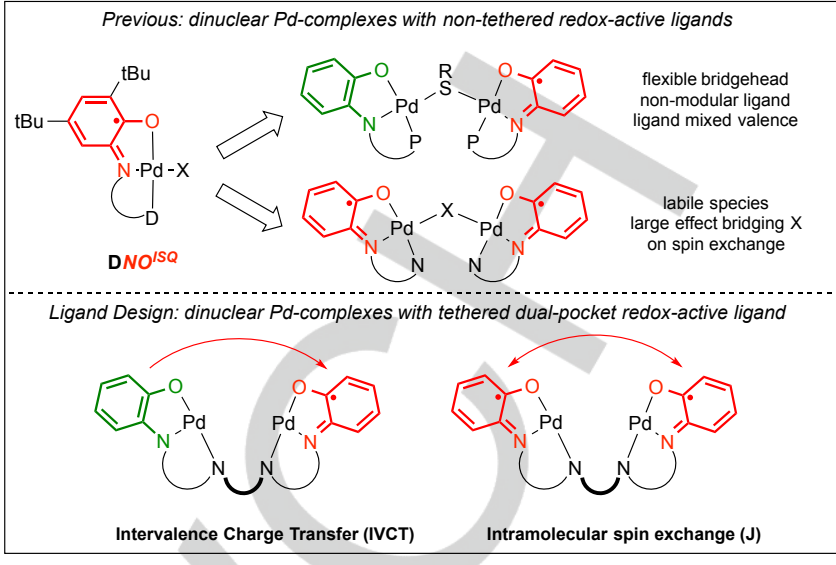

Figure 2. Schematic illustration of previously reported complexes (top) and the targeted bimetallic complexes with a dinucleating ligand scaffold bearing two redox-active o-aminophenol-derived binding pockets (bottom).

Herein we describe the synthesis of a dinucleating redox-active ligand $\mathrm{L}^{\mathrm{H} 4}$ bearing a triazole linker and the corresponding dinuclear mixed valent $\mathrm{Pd}(\mathrm{II})$ complexes bridged by a chlorido or 1,1-azido ligand. . Five different ligand oxidation states were found to be accessible in a narrow range of $1 \mathrm{~V}$. A combined spectroscopic, crystallographic, spectroelectrochemical, magnetochemical and computational study on these complexes elucidates the electronic communication between the two redoxactive moieties in $\mathrm{L}^{\mathrm{H} 4}$ in different oxidation states, displaying intra-ligand antiferromagnetic coupling as well as intervalence charge transfer (IVCT), depending on the ligand oxidation state. 


\section{Results and Discussion}

\section{Complex Synthesis and Characterization.}

We envisioned that the triazole-containing ligand $\mathrm{L}^{\mathrm{H} 4}$ featuring two NNO binding pockets (Scheme 2) could harbour two Pd(II) ions in close enough proximity for cooperative (magnetic) behavior, likely aided by coordination of a bridging co-ligand between both pockets. A convergent synthetic route involving connection of an aminophenol-derived azide and an alkyne via the copper(I)-catalyzed azide-alkyne cycloaddition (CuAAC) failed to deliver the desired compound, likely due to aminophenol coordination to copper. ${ }^{[21]}$ Therefore, an alternative synthesis of $\mathrm{L}^{\mathrm{H} 4}$ was undertaken, starting with the CuAAC of 2azidoaniline (1) with 2-ethynyl aniline (2) to afford diamine 3 in good yield (Scheme 1). Subsequent condensation with two equivalents of 1,3-di(tert-butyl)catechol afforded $\mathrm{L}^{\mathrm{H} 4}$ as an airstable off-white solid in good yield.

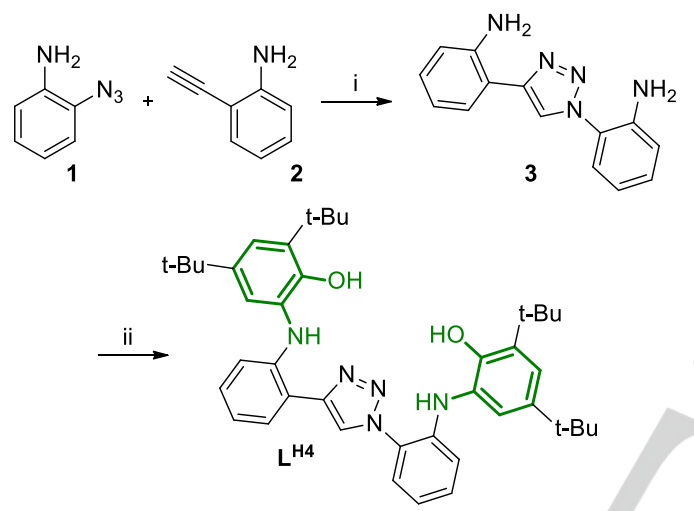

Scheme 1. Synthesis of dinucleating ligand $\mathrm{L}^{\mathrm{H} 4}$. Reagents and conditions: (i) $\mathrm{CuSO}_{4}$, sodium ascorbate, THF/EtOH/ $\mathrm{H}_{2} \mathrm{O}, 70{ }^{\circ} \mathrm{C}$, (ii) 1,3-di(tert-butyl)catechol (2 eq.), $\mathrm{AcOH}, \mathrm{CH}_{2} \mathrm{Cl}_{2} /$ hexanes, r.t.

Careful dropwise addition of a dilute solution of $\mathrm{L}^{\mathrm{H} 4}$ and $\mathrm{NEt}_{3}$ to an excess of $\left[\mathrm{PdCl}_{2}(\mathrm{NCMe})_{2}\right]$ under aerobic conditions, followed by purification by column chromatography, allowed for isolation of dark-colored paramagnetic complex 4 (Scheme 2). ${ }^{[22]}$ Field desorption mass spectrometry (FD-MS) indicated the formation of a dinuclear species with one chlorido-ligand ( $\mathrm{m} / \mathrm{z} 904.15483$ for $[\mathrm{M}]^{+}$). Dinuclear complex $\mathbf{4}$ could be smoothly converted to paramagnetic 1,1-azido complex 5 by salt metathesis with sodium azide. A characteristic bridging-azide stretch was observed at $2082 \mathrm{~cm}^{-1}$ in the IR spectrum of complex $\mathbf{5}$, similar to our previously reported dinuclear azido-bridged palladium complex. ${ }^{[11]}$ Magnetic susceptibility measurements using the Evans' method gave an effective magnetic moment $\left(\mu_{\text {eff }}\right)$ of 1.61 $\mu_{\mathrm{B}}(4)$ and $1.59 \mu_{\mathrm{B}}(5)$, indicating an $S=1 / 2$ ground state. $X$-band EPR spectroscopy at room temperature revealed strong isotropic signals at $g=2.0012$, supporting the presence of a ligand-centered radical in both compounds (Figure S1). No wellresolved hyperfine couplings were observed at room temperature or at $20 \mathrm{~K}$ (Figure S4). The observed MS data, the observed $S=1 / 2$ spin state and the ligand-centered radical character can only be explained by ligand-based mixed valence in these systems, with one $N_{N O}{ }^{\text {ISQ }}$ fragment and one NNO $^{\text {AP }}$ fragment per complex. Hence, this dinucleating ligand system undergoes rare spontaneous site-selective oxidation to generate a mixed valent binding mode.

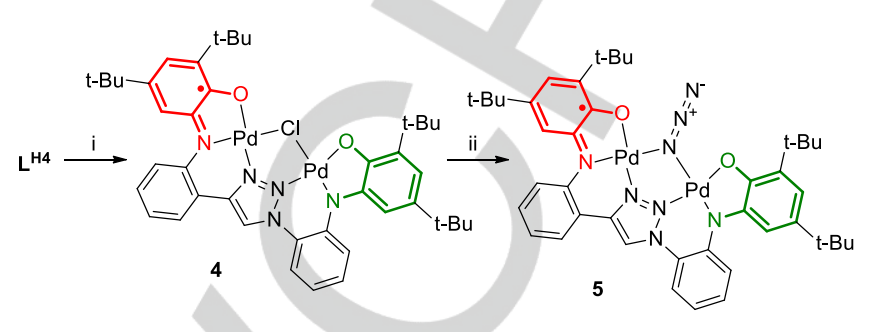

Scheme 2. Synthesis of complexes $\mathbf{4}$ and $\mathbf{5}$. Reagents and conditions: i) 4 eq $\left[\mathrm{PdCl}_{2}\left(\mathrm{MeCN}_{2}\right], \mathrm{NEt}_{3}, \mathrm{MeOH}\right.$, rt; ii) $\mathrm{NaN}_{3}, \mathrm{MeOH}$, r.t.

Black single crystals of $\mathbf{4}$ and $\mathbf{5}$ suitable for X-ray structures determination were grown by vapor diffusion of hexane into an $\mathrm{EtOH}$ solution and by slow evaporation of a $\mathrm{CH}_{2} \mathrm{Cl}_{2} / \mathrm{THF}$ mixture, respectively. The structures depicted in Figure 3 each show one of the respective crystallographically independent molecules in the unit cell. Although all independent molecules in the unit cells are chemically identical, differences in structural conformations occur in the solid state (concave vs. twisted over the iminosemiquinonate-triazole-amidophenolate plane). All show slightly distorted square planar geometries for the $\mathrm{Pd}$ atoms with a $\kappa^{2}-N, N$ ' bridging triazole and a $\mu$-chlorido or $\mu$-azido ligand. To the best of our knowledge, this is only the second example of a structurally characterized complex with a triazole acting as bridging ligand to a non-coinage metal. ${ }^{[23]}$

Brown's metrical oxidation state (MOS) method, which allows for quantification of the oxidation state of o-aminophenol-derived ligands by analysis of the $\mathrm{C}-\mathrm{C} \mathrm{C}-\mathrm{O}$ and $\mathrm{C}-\mathrm{N}$ bond lengths, ${ }^{[24]}$ has proven to be a reliable method to gain information about the ligand oxidation state in these $\mathrm{Pd}(\mathrm{NNO})$ complexes. ${ }^{[17-19]} \mathrm{We}$ typically find slight deviations for the $\mathrm{NO}^{\mathrm{AP}}$ oxidation state (MOS $=-1.7--1.9$ ) but these values are clearly discernable from those corresponding to the $\mathrm{NO}^{\mathrm{ISQ}}$ oxidation state (MOS $=-0.9--1.1$ ). At first glance the MOS values do not to support the mixed valent assignments for all independent molecules in the asymmetric units of $\mathbf{4}$ and $\mathbf{5}$, as some tend toward intermediate oxidation states for both rings. However, the $\kappa^{2}-N, N^{\prime}$ triazole rings are disordered over two orientations - multiplying the occupancy factors with the theoretical oxidation states (see SI for more information) results in MOS values in agreement with ligand-based mixed valent complexes, with Ring $A$ and Ring $B$ being in the amidophenolate $\left(\mathbf{A P}^{2-}\right)$ and iminosemiquinonato (ISQ) oxidation state, respectively. 


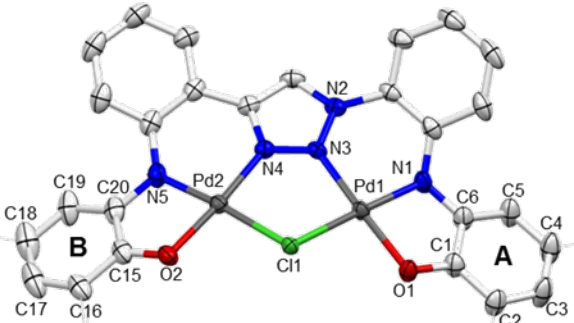

Ring A

\begin{tabular}{ccccc} 
& \multicolumn{2}{c}{$\mathbf{4}$} & \multicolumn{2}{c}{$\mathbf{5}$} \\
Bond & XRD $(\boldsymbol{\AA})$ & DFT $(\boldsymbol{\AA})$ & XRD $(\boldsymbol{\AA})$ & DFT $(\boldsymbol{\AA})$ \\
\hline \hline C1-C2 & $1.418(4)$ & 1.418 & $1.422(4)$ & 1.410 \\
C2-C3 & $1.392(4)$ & 1.390 & $1.383(5)$ & 1.386 \\
C3-C4 & $1.410(4)$ & 1.405 & $1.404(5)$ & 1.403 \\
C4-C5 & $1.378(4)$ & 1.387 & $1.385(5)$ & 1.388 \\
C5-C6 & $1.401(4)$ & 1.399 & $1.416(5)$ & 1.403 \\
C6-C1 & $1.425(4)$ & 1.411 & $1.432(5)$ & 1.413 \\
C1-O1 & $1.332(3)$ & 1.334 & $1.314(4)$ & 1.332 \\
C6-N1 & $1.389(4)$ & 1.414 & $1.393(4)$ & 1.410 \\
Pd1-N1 & $1.957(2)$ & 1.963 & $1.967(3)$ & 1.984 \\
Pd1-O1 & $1.973(2)$ & 1.987 & $1.975(2)$ & 1.961 \\
Pd1-N3 & $1.987(2)$ & 1.998 & $1.967(2)$ & 1.982 \\
MIOS & $-1.51 \pm 0.06$ & $-1.70 \pm 0.13$ & $1.83 \pm 0.11$ & $-1.67 \pm 0.12$
\end{tabular}

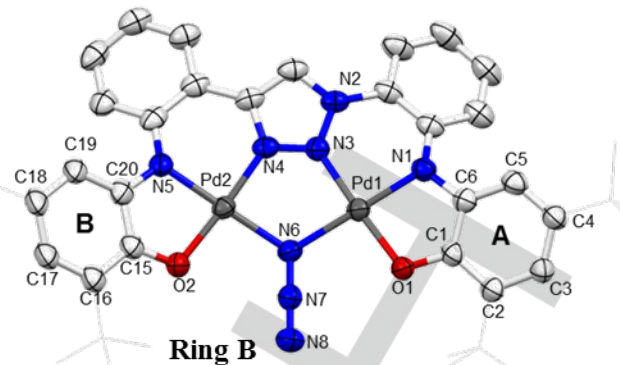

4

\begin{tabular}{lcccc} 
Bond & XRD $(\AA)$ & DFT $(\AA)$ & XRD $(\AA)$ & DFT $(\AA)$ \\
\hline
\end{tabular}

$\begin{array}{lllll}\text { C15-C16 } & 1.418(4) & 1.432 & 1.413(4) & 1.422 \\ \text { C16-C17 } & 1.395(4) & 1.377 & 1.399(4) & 1.375\end{array}$

$\begin{array}{lllll}\mathrm{C17}-\mathrm{C} 18 & 1.405(5) & 1.424 & 1.395(5) & 1.419\end{array}$

$\begin{array}{lllll}\mathrm{C} 18-\mathrm{C} 19 & 1.380(6) & 1.375 & 1.390(5) & 1.377\end{array}$

$\begin{array}{lllll}\mathrm{C} 19-\mathrm{C} 20 & 1.400(4) & 1.412 & 1.396(4) & 1.414\end{array}$

$\begin{array}{lllll}\mathrm{C} 20-\mathrm{C} 15 & 1.415(4) & 1.442 & 1.417(4) & 1.444\end{array}$

$\begin{array}{lllll}\mathrm{C} 15-\mathrm{O} 2 & 1.335(3) & 1.300 & 1.343(3) & 1.303\end{array}$

$\begin{array}{lllll}\text { C20-N5 } & 1.400(4) & 1.373 & 1.416(4) & 1.375\end{array}$

$\begin{array}{lllll}\text { Pd2-N5 } & 1.953(2) & 2.007 & 1.973(2) & 2.005\end{array}$

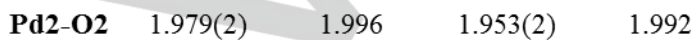

$\begin{array}{lllll}\text { Pd2-N4 } 1.972(2) & 1.995 & 1.973(2) & 1.986\end{array}$

MOS $-1.63 \pm 0.09-1.07 \pm 0.07-1.38 \pm 0.12-1.14 \pm 0.08$

Figure 3. Displacement ellipsoid plots (50\% probability level) of one of the independent molecules of both complexes $\mathbf{4}$ and $\mathbf{5}$ in the respective asymmetric unit. Hydrogen atoms and lattice solvent molecules are omitted and tBu groups are depicted as wireframes for clarity. The tabulated values are selected bond lengths ( $\AA$ ) obtained from XRD measurements and DFT calculations (b3-lyp, def2-TZVP).

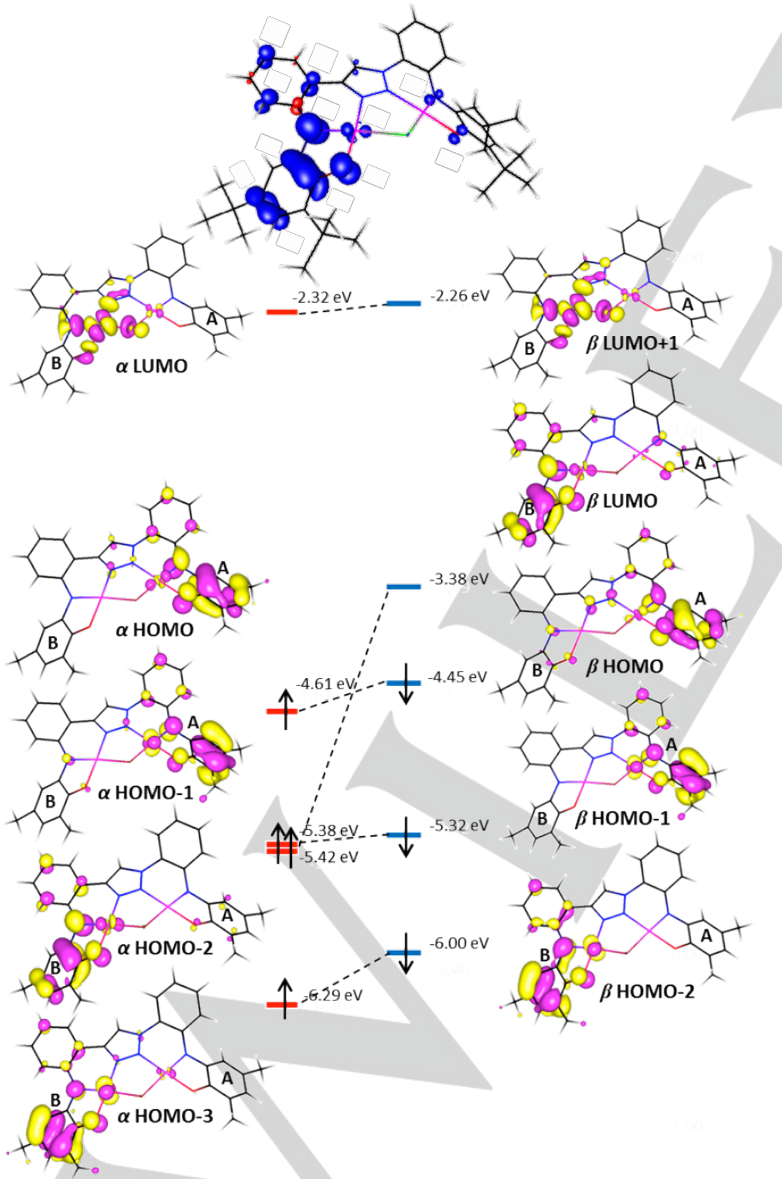

The DFT optimized geometries (b3-lyp, def2-TZVP) of 4 and $\mathbf{5}$ are in good agreement with the experimentally observed structures, except for the disorder in the triazole orientation (Figure 3). A clear localization of the ligand-centered radicals on Ring $B$ is observed in the spin-density plots of 4 and 5 (Figure 4 top, for $\mathbf{5}$ see Figure S16), which is in good agreement with the crystal structures. The minor delocalization toward the oxygen and nitrogen of ring $A$, which is most likely enabled by the large conjugated system ligand system, could indicate facile electronic coupling between the two mixed valent redox-active pockets. The difference in the MOS values for the DFT optimized structure clearly supports ligand-based mixed valence. Analysis of the molecular orbitals (Figure 4, bottom) reveals a singly occupied orbital (SOMO) on ring B (a HOMO-2, empty corresponding orbital: $\beta$ LUMO), whereas an analogous orbital on ring $A$ is doubly occupied, further underlining the ligandbased mixed valent assignment. As both rings $A$ and $B$ are highly similar, we propose that the localization of ligand oxidation states is due to a subtle electronic difference. The slightly less electron-withdrawing nature of the ortho-C4-triazole on the phenyl ring attached to redox-active ring $B$ makes it more electron-rich than ring $A$. Hence, the relative reduction potential of ring $B$ is higher than that of its counterpart, resulting in a more stabilized $\mathbf{N O}^{\text {ISQ }}$ ligand radical.

Figure 4. Top: DFT (b3-lyp/def2-TZVP) calculated spin-density plot for 4 Bottom: Molecular orbital diagram showing a singly occupied orbital on ring $\mathbf{B}$. 


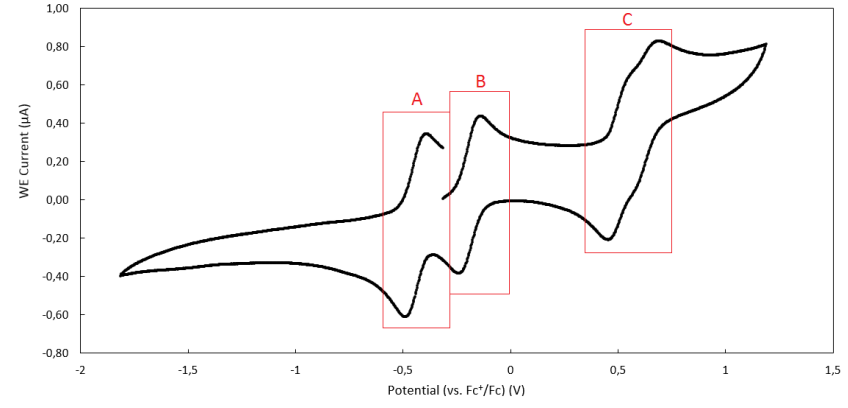

Figure 5. Cyclic voltammogram of 4 in $\mathrm{CH}_{2} \mathrm{Cl}_{2}\left(1 \times 10^{-3} \mathrm{M}\right)$; scan rate $100 \mathrm{mV}$ $\mathrm{s}^{-1}$

Cyclic voltammetry of 4 in $\mathrm{CH}_{2} \mathrm{Cl}_{2}$ showed three reversible consecutive one-electron oxidations and a single one-electron reduction event (Figure 5). The relatively low potential of the one-electron reduction $\left(E_{1 / 2}^{\text {red }}=-0.45 \mathrm{~V}\right.$ vs. $\left.\mathrm{Fc} / \mathrm{Fc}^{+}\right)$likely corresponds to a ligand-centered reduction to $4^{-}$with two $\mathrm{NO}^{\mathrm{AP}}$ pockets (A, Scheme 3 ). The one-electron anodic wave to $4^{+}$(B, $\left.E_{1 / 2}^{\text {ox }}=-0.20 \mathrm{~V} v \mathrm{Fc} / \mathrm{Fc}^{+}\right)$is almost fully separated from the oneelectron cathodic wave to $4^{-}$. The barely separated reversible oxidation events at $E_{1 / 2}=+0.50 \mathrm{~V}$ and $+0.63 \mathrm{~V} \mathrm{vs}$. $\mathrm{Fc}_{\mathrm{Fc}}{ }^{+}$(C) likely correspond to oxidation of $4^{+}$to $4^{2+}$ and $4^{3+}$, respectively (Scheme 4). The observation of these four one-electron redox processes indicates that all five ligand oxidation states are accessible within a relatively narrow potential window of just over $1 \mathrm{~V}$. The cyclic voltammogram of $\mathbf{5}$ in $\mathrm{CH}_{2} \mathrm{Cl}_{2}$ is nearly identical to that of 4 , showing only a slight shift of ca. $0.1 \mathrm{~V}$ for all redox events to more negative potentials. The direction of the shift is opposite to what was observed for mononuclear $\mathrm{PdCl}\left(\mathbf{N N O}^{\mathbf{I S Q}}\right)$ upon transformation to the corresponding azide complex. ${ }^{[19]}$
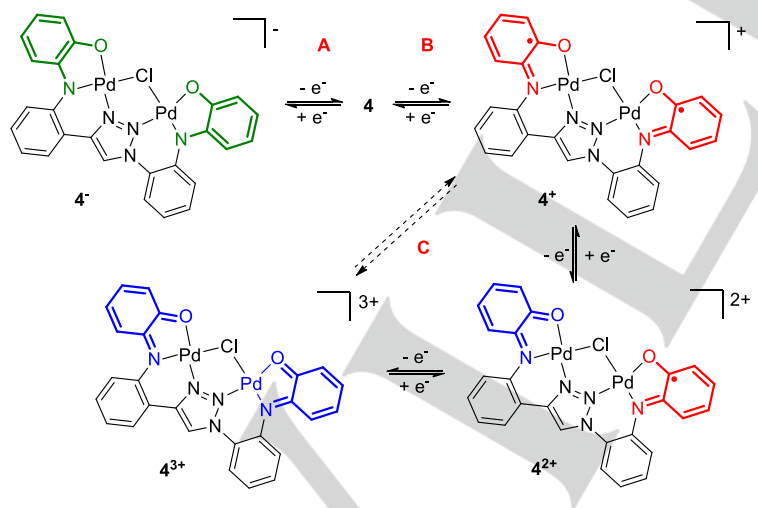

Scheme 3. The five-membered redox series based on complex 4 observed by cyclic voltammetry (A-C). The $t$ Bu groups are omitted for clarity.

\section{Spectroelectrochemistry and TD-DFT.}

To gain insight into the reversible redox events observed by cyclic voltammetry and to identify the envisaged IVCT transitions for the mixed valence species, complexes $\mathbf{4}$ and $\mathbf{5}$ were studied by UV-Vis-NIR and FT-IR spectroelectrochemistry (SEC) using an optically transparent thin-layer electrochemical (OTTLE) cell. As the spectroscopic data obtained for $\mathbf{4}$ and $\mathbf{5}$ is very similar, only results obtained with complex $\mathbf{5}$ will be discussed here, as the azide co-ligand offers an additional spectroscopic handle (data related to 4 can be found in the SI). One-electron reduction of 5 to $5^{-}$proved to be fully reversible on the SEC timescale, as complete regeneration of the parent species was observed in the UV-Vis-NIR spectra upon re-oxidation (Figure 6). An increase of the band at $28000 \mathrm{~cm}^{-1}$ is observed and the broad absorption at $\sim 9000 \mathrm{~cm}^{-1}$, which is attributed to an intraligand CT involving the $\mathbf{N O}^{\mathbf{I S Q}}$ moiety (vide infra), disappeared upon reduction. A minor decrease in absorption at lower energies $\left(\sim 5500 \mathrm{~cm}^{-1}\right)$ was also observed. In FT-NIR spectroelectrochemistry, reduction coincides with disappearance of an IVCT absorption band in the range $3000-7000 \mathrm{~cm}^{-1} .{ }^{[25]}$ In line with this assignment, this band also disappears on oxidation of $\mathbf{5}$ to the corresponding cation (see below). Another interesting observation is the subtle shift of the azide stretching frequency from $2087 \mathrm{~cm}^{-1}$ to $2083 \mathrm{~cm}^{-1}$ upon reduction (Figure 7, right), indicating that the negatively charged bridging ligand is not significantly involved in the cathodic step.

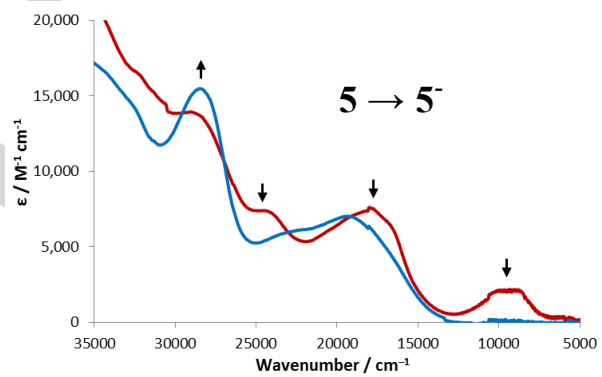

Figure 6. UV-Vis-NIR spectra before (blue) and after one-electron reduction (red) of complex $\mathbf{5}$ to $\mathbf{5}^{-}$, showing the disappearance of the intraligand $\left(\mathbf{N O}^{\text {ISQ }}\right.$ ) CT band at ca. $9000 \mathrm{~cm}^{-1}$. Spectra recorded in $\mathrm{CH}_{2} \mathrm{Cl}_{2}$ containing $0.3 \mathrm{M}[\mathrm{N}(n-$ $\mathrm{Bu})_{4} \mathrm{PF}_{6}$ and $2 \mathrm{mM}$ complexes.

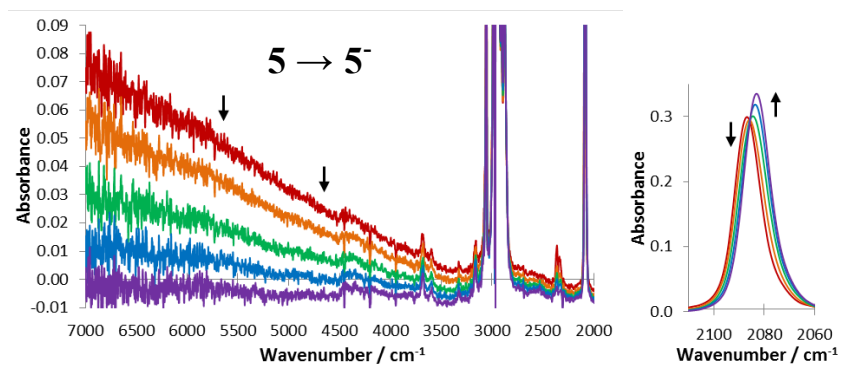

Figure 7. Left: FT-IR spectra recorded upon one-electron reduction of $\mathbf{5}$ to $\mathbf{5}$, showing the disappearance of the broad IVCT band (an NO ISQ $^{\text {IS }}$ NO $^{\text {AP }}$ electron transfer). Right: zoom-in of the azide stretch region. Spectra recorded in $\mathrm{CH}_{2} \mathrm{Cl}_{2}$ containing $0.3 \mathrm{M}\left[\mathrm{N}(n-\mathrm{Bu})_{4}\right] \mathrm{PF}_{6}$ and $10 \mathrm{mM}$ complex.

The first reversible one-electron oxidation of 5 to $5^{+}$(and 4 to $\mathbf{4}^{+}$) was also probed by spectroelectrochemistry, to assess the origin of the respective band at ca. $9000 \mathrm{~cm}^{-1}$ (proposed to arise from 
intraligand CT) and the small absorption band at ca. 3000-7000 $\mathrm{cm}^{-1}$ (due to intramolecular IVCT) (Figure 8). Upon oxidation, the band at ca. $9000 \mathrm{~cm}^{-1}$ increased in intensity, which is in accordance with intraligand CT within the $\mathrm{NO}^{\text {ISQ }}$ chromophore, as an additional $\mathbf{N O}^{\text {ISQ }}$ is created upon the oxidation to $4^{+}$and $5^{+}$ The weak absorption band at ca. $3000-7000 \mathrm{~cm}^{-1}$ is indeed absent after the oxidation, complying with its assignment to an intramolecular IVCT process. This is also supported by IR spectroelectrochemistry, which revealed identical spectral changes in the IVCT region as for the one-electron reduction (Figure 9). ${ }^{[26]}$ In agreement with the blue shift of the azide stretching frequency observed for the one-electron reduction of 5, a shift to smaller wavenumber (from 2087 to $2093 \mathrm{~cm}^{-1}$ ) is observed upon the oxidation to $\mathbf{5}^{+}$(Figure 9 , right).

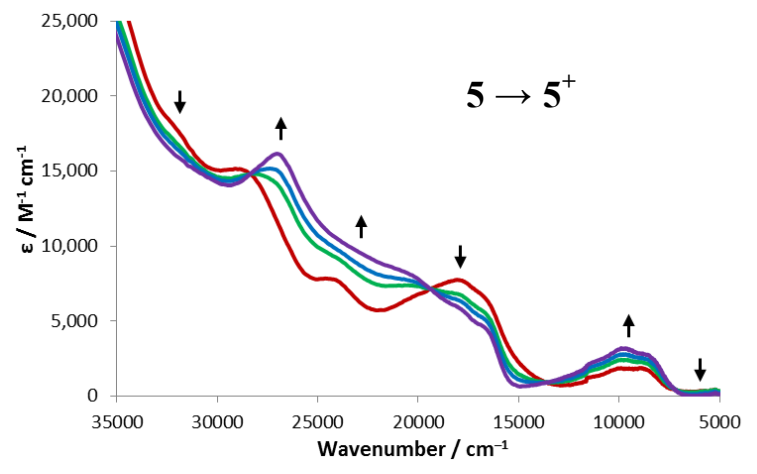

Figure 8. UV-Vis-NIR spectral changes accompanying the one-electron oxidation of $\mathbf{5}$ to $\mathbf{5}^{+}$, showing the increase in the intraligand CT band at ca. $9000 \mathrm{~cm}^{-1}$ and the disappearance of the IVCT band (see in detail in Figure 10) Spectra recorded in $\mathrm{CH}_{2} \mathrm{Cl}_{2}$ with $0.3 \mathrm{M}\left[\mathrm{N}(n-\mathrm{Bu})_{4}\right] \mathrm{PF}_{6}$ at a concentration of 2 $\mathrm{mM}$.
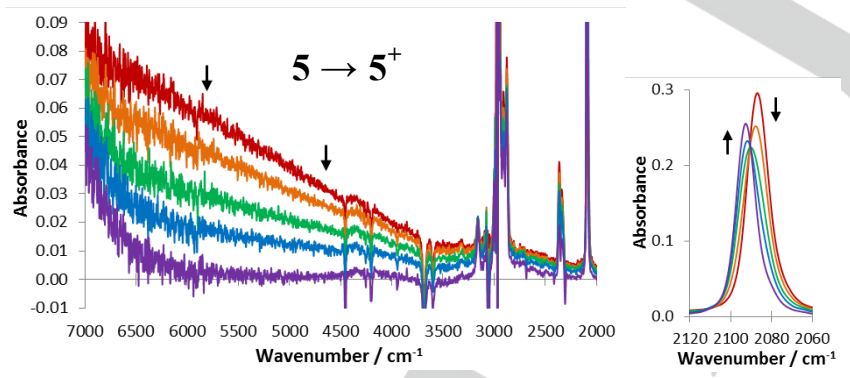

Figure 9. Left: FT-IR spectra recorded upon the one-electron oxidation of $\mathbf{5}$ to $\mathbf{5}^{\mathbf{+}}$, showing the disappearance of the small IVCT band. Right: zoom-in of the azide stretch region. Spectra recorded in $\mathrm{CH}_{2} \mathrm{Cl}_{2}$ containing $0.3 \mathrm{M}[\mathrm{N}(n-$ $\left.\mathrm{Bu})_{4}\right] \mathrm{PF}_{6}$ and $10 \mathrm{mM}$ complex.

The poorly separated second and third one-electron oxidation waves in the respective cyclic voltammograms prevented accurate characterization of the oxidized species $5^{2+}$ and $5^{3+}$ (as well as $4^{2+}$ and $4^{3+}$ ) using spectroelectrochemistry. Moreover, some decomposition of the dications occurred at lower scan rates. Nonetheless, a new intramolecular IVCT band (of fairly low intensity) appeared upon the anodic generation of $4^{2+}$ and
$5^{2+}$, which faded again with the ultimate formation of $4^{3+}$ and $5^{3+}$ (Figure S6 and S7). These spectral changes can be attributed to the mixed valent character of $4^{2+}$ and $5^{2+}$, which contain both a $\mathrm{NO}^{\text {ISQ }}$ and an $\mathrm{NO}^{\mathrm{IBQ}}$ fragment (see SI for details). In agreement with the absence of an NO $\mathrm{NQ}^{\mathrm{ISQ}}$ moiety upon oxidation to $4^{3+}$ and $5^{3+}$, the intraligand CT band at ca. $9000 \mathrm{~cm}^{-1}$ is replaced by a strong absorption at $15000 \mathrm{~cm}^{-1}$ (Figure S6).

TD-DFT calculations (ORCA, b3-lyp, def2-TZVP) were performed to confirm the origin of the intraligand charge-transfer band at ca. $9000 \mathrm{~cm}^{-1}$ and the broad intramolecular IVCT band in the deep NIR region. The calculated electronic transitions (Figure 10) nicely reproduced the experimental UV-Vis-NIR absorption spectra. Analysis of the molecular orbitals involved in the calculated transitions confirmed the presence of a lowenergy intramolecular IVCT band inherent to an excitation from the $\beta$ HOMO-1 (Figure 4), which is localized on ring $A$, to the $\beta$ LUMO, which is located on ring $B$. The gas-phase calculated IVCT band maximum at ca. $7000 \mathrm{~cm}^{-1}$ is at higher energy than the experimentally observed value, which is not uncommon for TD-DFT calculations. An intraligand charge transfer band at approximately $11000 \mathrm{~cm}^{-1}$ is attributed to an excitation from the $\beta$ HOMO-2 to the $\beta$ LUMO, both localized on ring $B$. This CT absorption shows vibronic progression, which is not reflected in the computed spectrum. The small blue shift of the azide stretching frequency upon oxidation of $\mathbf{5}$ to $\mathbf{5}^{+}$was also reproduced by DFT calculations. As different ligand oxidation states, namely $\mathbf{N O}^{\mathrm{ISQ}}$ and $\mathbf{N O}^{\mathrm{AP}}$, are observed in the solid state structures of $\mathbf{4}$ and $\mathbf{5}$ and measurable intramolecular IVCT bands are detected, both compounds can be classified as Robin Day Class II mixed valence compounds. However, due to the low energy required for interconversion of the two states, these systems can be considered as borderline to Class III systems.

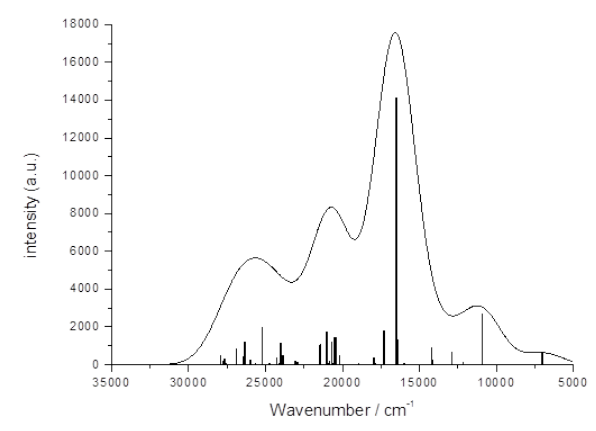

Figure 10. TD-DFT calculated electronic absorption spectrum for 5 (ORCA, b3-lyp, def2-TZVP). 
Isolation of diradical, one-electron oxidized analogues of 4 and 5 .

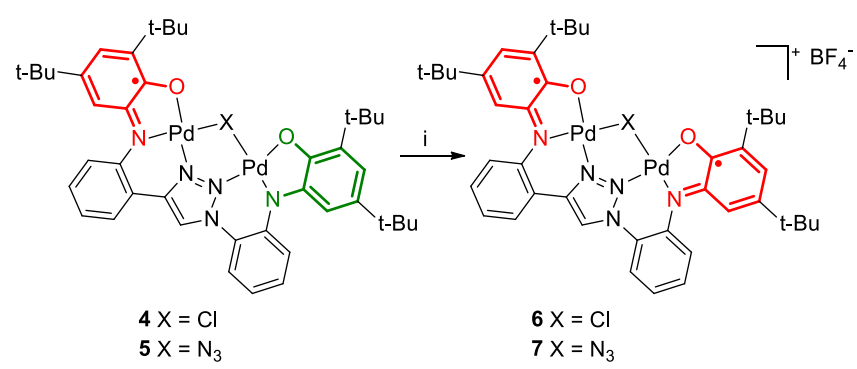

Scheme 4. One-electron oxidation of the ligand-based mixed valent complexes $\mathbf{4}$ and $\mathbf{5}$ to form diradicals $\mathbf{6}$ and $\mathbf{7}$. Reagents and conditions: i) acetylferrocenium tetrafluoroborate, $\mathrm{C}_{6} \mathrm{H}_{6}$, r.t.

Chemical one-electron oxidation of the ligand-based mixed valent complexes $\mathbf{4}$ and $\mathbf{5}$ using a stoichiometric amount of acetylferrocenium tetrafluoroborate $\left(\left[{ }^{\mathrm{Ac}} \mathrm{Fc}_{\mathrm{B}} \mathrm{BF}_{4}\right)\right.$ generated diradicals 6 and 7 (Scheme 4), which were isolated as dark paramagnetic solids. Only two broad signals around $\delta 17$ and 2 were observed for both compounds by ${ }^{1} \mathrm{H}$ NMR spectroscopy, which is in contrast with our previously reported dinuclear diradical complexes that displayed broad signals for all protons. ${ }^{[11]} \mathrm{CSI}-\mathrm{MS}$ studies showed the intact cationic fragments of $6\left(\mathrm{~m} / \mathrm{z} 904.1715[\mathrm{M}]^{+}\right)$and $7\left(\mathrm{~m} / \mathrm{z} 911.1869[\mathrm{M}]^{+}\right)$.

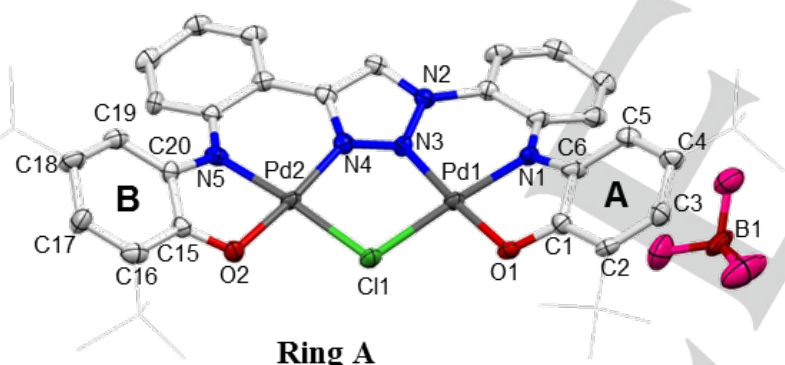

Ring A

6

\begin{tabular}{ccccc} 
Bond & XRD & DFT & XRD $(\AA)$ & DFT $(\AA)$ \\
\hline \hline C1-C2 & $1.424(11)$ & 1.433 & $1.425(5)$ & 1.426 \\
C2-C3 & $1.371(12)$ & 1.373 & $1.368(6)$ & 1.370 \\
C3-C4 & $1.418(12)$ & 1.430 & $1.432(5)$ & 1.426 \\
C4-C5 & $1.348(12)$ & 1.374 & $1.372(5)$ & 1.377 \\
C5-C6 & $1.424(12)$ & 1.406 & $1.409(6)$ & 1.412 \\
C6-C1 & $1.463(11)$ & 1.446 & $1.442(5)$ & 1.448 \\
C1-O1 & $1.300(10)$ & 1.298 & $1.311(5)$ & 1.298 \\
C6-N1 & $1.347(10)$ & 1.370 & $1.372(5)$ & 1.369 \\
Pd1-N1 & $1.974(6)$ & 1.986 & $1.966(3)$ & 2.993 \\
Pd1-O1 & $1.984(6)$ & 1.983 & $1.972(3)$ & 1.989 \\
Pd1-N3 & $1.989(6)$ & 2.008 & $1.966(3)$ & 1.994
\end{tabular}

MOS $-0.86 \pm 0.11-1.03 \pm 0.08-1.11 \pm 0.08-1.03 \pm 0.08$
In agreement with the spectroelectrochemical experiments, the strong azide IR-stretch shifted to a larger wavenumber at 2086 $\mathrm{cm}^{-1}\left(\Delta v=4 \mathrm{~cm}^{-1}\right)$ and no intramolecular IVCT band was observed. X-band EPR spectroscopy at room temperature revealed strong isotropic signals with no resolved hyperfine couplings at $g=2.0012$ and $g=2.0011$ for 6 and 7 , respectively, supporting the preservation of ligand-centered radical character in both complexes (Figure S2). Strikingly, the EPR signal intensity decreased significantly (to approx. half of the original intensity, Figure S3) upon the oxidation of the monoradicals (4 and 5 ) to the diradicals ( 6 and 7 ), which could indicate partial anti-ferromagnetic coupling of the two radicals in 6 and 7 . Crystals suitable for X-ray structure determination of both $\mathbf{6}$ and 7 were obtained by vapor diffusion of pentane into their solution in toluene. The cationic fragments in the crystal structures of 6 and 7 (Figure 11) are almost isostructural to those of $\mathbf{4}$ and $\mathbf{5}$, showing slightly distorted square planar geometries around the $\mathrm{Pd}$ atoms with $\mathrm{K}^{2}-N, N^{\prime}$ bridging triazoles disordered over two orientations. Two crystallographically independent molecules are found in the asymmetric unit of $6\left(Z^{\prime}=2\right)$ with metric parameters and MOS values for the redox-active ring fragments in agreement with two pairs of $\mathbf{N O}^{\mathrm{ISQ}}$ ligand radicals (Figure 11). The MOS values for both rings in 7 are also in agreement with two $\mathbf{N O}^{\text {ISQ }}$ ligand radicals. Notably, the azido ligand is positioned out of the ligand metal plane to a greater extent than observed for 5 . Closer analysis of the crystal packing revealed a close contact between the bridging azido moiety and another molecule of 7 .

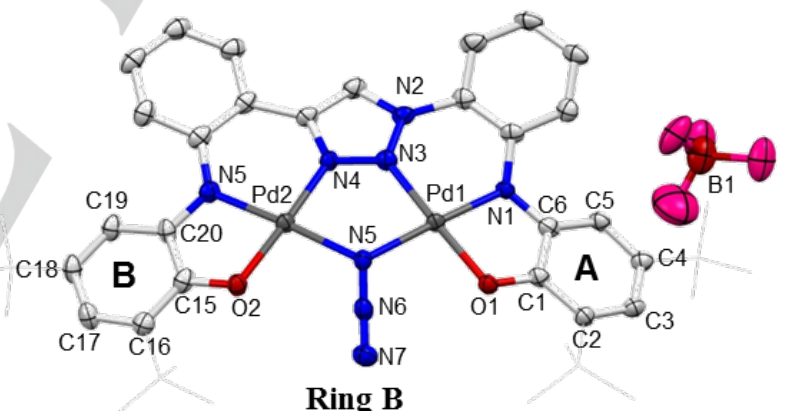

\begin{tabular}{ccccc} 
Bond & XRD & DFT & XRD $(\boldsymbol{\AA})$ & DFT $(\boldsymbol{\AA})$ \\
\hline C15-C16 & $1.415(12)$ & 1.431 & $1.415(6)$ & 1.425 \\
C16-C17 & $1.387(12)$ & 1.374 & $1.376(6)$ & 1.371 \\
C17-C18 & $1.458(12)$ & 1.430 & $1.439(6)$ & 1.425 \\
C18-C19 & $1.364(13)$ & 1.373 & $1.363(3)$ & 1.375 \\
C19-C20 & $1.412(11$ & 1.410 & $1.407(5)$ & 1.415 \\
C20-C15 & $1.454(11)$ & 1.446 & $1.447(5)$ & 1.446 \\
C15-O2 & $1.285(10)$ & 1.298 & $1.317(5)$ & 1.300 \\
C20-N5 & $1.383(11)$ & 1.369 & $1.377(5)$ & 1.369 \\
Pd2-N5 & $1.975(7)$ & 1.993 & $1.972(3)$ & 2.001 \\
Pd2-O2 & $1.976(6)$ & 1.982 & $1.967(3)$ & 1.987 \\
Pd2-N4 & $1.985(7)$ & 2.005 & $1.965(3)$ & 1.990
\end{tabular}

MOS $-0.95 \pm 0.17-1.03 \pm 0.07-1.17 \pm 0.11 \quad-1.05 \pm 0.07$

Figure 11. Top: Displacement ellipsoid plots (50\% probability level) of one of the two crystallographically independent molecules in the asymmetric unit of complexes 6 (left) and 7 (right). Hydrogen atoms and lattice solvent molecules are omitted for clarity. Bottom: Selected bond lengths ( $\AA$ ) obtained from XRD and DFT calculations (b3-lyp, def2-TZVP). 

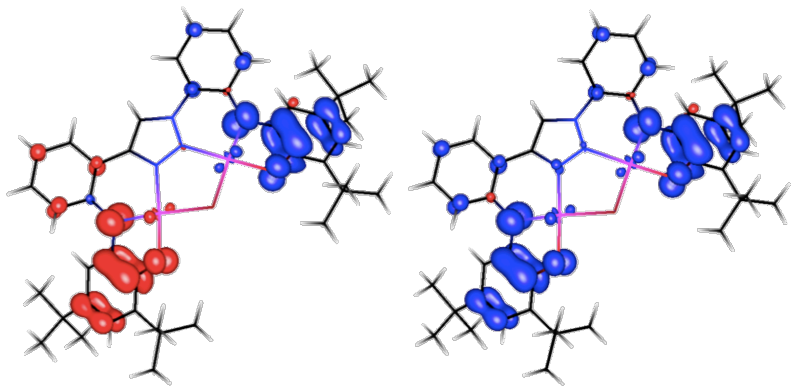

Figure 12. Spin density plots of the DFT optimized (b3-lyp, def2-TZVP) spin states of mono-oxidized complex 6: OSS (left) and triplet (right) (For 7 see Figure S15).CSS spin states not displayed.

The experimental metric parameters of 6 and 7 are wellreproduced by the DFT optimized geometries in the closed-shell singlet (CSS), open-shell singlet (OSS) and triplet spin states. Similar to the non-tethered dinuclear diradical complexes with a single bridging (pseudo)halide ligand reported previously, ${ }^{[19]}$ the OSS and triplet spin states lie very close in energy, with the former being slightly lower in energy (for 6: $E_{\mathrm{OSS}}-E_{\mathrm{T}}=-0.15$ kcal mol ${ }^{-1}$; for 7 : $\left.E_{\mathrm{OSs}}-E_{\mathrm{T}}=-0.19 \mathrm{kcal} \mathrm{mol}^{-1}\right)$. The CSS solutions are 12.3 and $11.9 \mathrm{kcal} \mathrm{mol}^{-1}$ higher in energy than the OSS solutions for 6 and 7 , respectively. The spin density plots of the OSS and triplet solutions for both systems reflect the diradical character of these systems (Figure 12). The triazole linker facilitates delocalization of both spins over the entire conjugated ligand framework in the OSS spin density plots, which was not observed for the non-tethered chlorido-bridged diradical analogue. This difference could have consequences for the magnetic interaction between the two redox-active pockets in these diradical compounds.

\section{Magnetic behavior of complexes 6 and 7 in the solid} state.

The intramolecular spin-exchange coupling $(J)$ of the dinuclear diradicals in the non-tethered systems was significantly affected by the nature of the bridging (pseudo-)halide ligand. ${ }^{[19]}$ Using the rigid and conjugated dinucleating redox-active ligand $L$ in $\mathbf{6}$ and 7 might overrule this bridging co-ligand effect. Magnetic measurements were performed on polycrystalline samples of both species using a SQUID magnetometer. The $X_{\mathrm{M}} T$ value at room temperature for both 6 and 7 is around $0.6 \mathrm{~cm}^{3} \mathrm{~mol}^{-1} \mathrm{~K}$, corresponding to an effective magnetic moment of approx. 2.2 $\mu_{\mathrm{B}}$. Upon lowering the temperature, $\chi_{\mathrm{M}} T$ approaches to zero, revealing a singlet ground state (Figure 13). The $X_{\mathrm{M}}$ vs. $T$ plots (Figure 13, insets) exhibit broad maxima at 65 and $55 \mathrm{~K}$ for 6 and 7 , respectively, indicating an anti-ferromagnetic (AF) interaction. Modeling of the experimental data, using a fitting procedure to the Heisenberg-Dirac-van-Vleck (HDvV) spin Hamiltonian for isotropic exchange coupling and Zeeman splitting (Eq. (1)), leads to exchange coupling constants $J$ of -39 and $-29 \mathrm{~cm}^{-1}$ for 6 and 7 , respectively.

$$
\hat{H}=-2 J \hat{S}_{1} \hat{S}+g \mu_{B} \vec{B}\left(\vec{S}_{1}+\vec{S}_{2}\right)
$$

The experimental singlet-triplet energy gaps $\Delta E_{\mathrm{S}-\mathrm{T}}$ (equal to $2 \mathrm{~J}$ ) are $-77 \mathrm{~cm}^{-1}$ or $-0.22 \mathrm{kcal} \mathrm{mol}^{-1}$ for 6 and $-59 \mathrm{~cm}^{-1}$ or -0.17 kcal $\mathrm{mol}^{-1}$ for 7 , confirming singlet ground states for both complexes with a weak spin-exchange interaction. These observations are supported by the DFT calculations, predicting a similarly weak $A F$ exchange coupling constant for both complexes (b3-lyp, def2-TZVP: $J=-35.6 \mathrm{~cm}^{-1}$ for 6 and -43.1 $\mathrm{cm}^{-1}$ for 7 ).
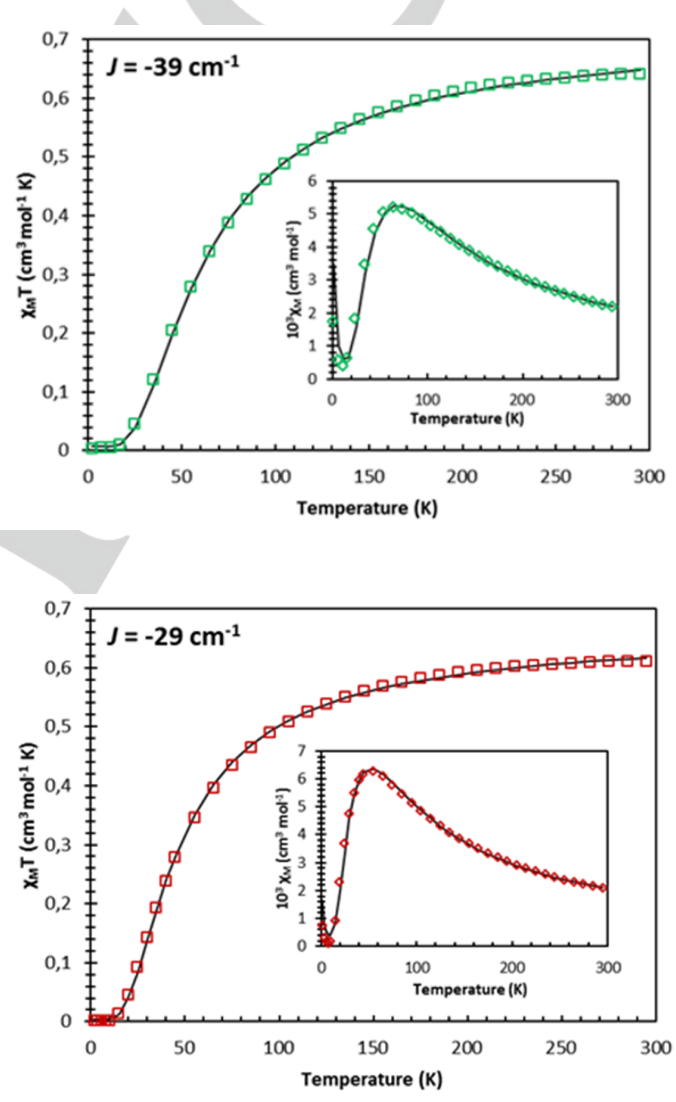

Figure 13. Temperature dependence of $X_{M} T$ and $X_{M}$ (insets) for complex 6 (top) and 7 (bottom). Squares: experimental data. Lines: fitted data.

\section{Conclusions}

We report the facile two-step synthesis of a new dinucleating redox-active ligand $\left(\mathrm{L}^{\mathrm{H} 4}\right)$ bearing two $\mathrm{NNO}^{\mathrm{H} 2}$ binding pockets and a 1,2,3-triazole linker. Coordination of this ligand to $\mathrm{Pd}(\mathrm{II})$ under aerobic conditions and in the presence of a base results in isolation of paramagnetic ligand-based mixed valent dinuclear Pd complex 4, featuring a $\mathrm{K}^{2}-N, N^{\prime}$ bridging triazole unit and a bridging chlorido co-ligand. The corresponding $\mu$-1,1-azido analogue 5 is prepared via salt metathesis of 4 with $\mathrm{NaN}_{3}$. Both species are crystallographically characterized, revealing the 
presence of one NO ${ }^{\text {ISQ }}$ and one $\mathbf{N O}^{\mathrm{AP}}$ fragment in the ligand framework. Five different ligand oxidation states were accessible by (spectro)electrochemistry. A combined spectroscopic, crystallographic, spectroelectrochemical, magnetochemical and computational study on these complexes elucidates the electronic communication between the two redox-active moieties in $\mathrm{L}^{\mathrm{H} 4}$ in different oxidation states, resulting in Robin-Day Class II ligand-based mixed valence with little influence upon changing the bridging (pseudo)halide ligand. Intra-ligand charge transfer bands as well as intervalence charge transfer (IVCT) bands are observed in the NIR and mid-IR region. Selective one-electron oxidation allowed for isolation of the corresponding cationic diradicals, which engage in anti-ferromagnetic coupling, as deduced from SQUID and EPR measurements. In stark contrast with our previously reported non-tethered diradical systems, no significant influence of the bridging co-ligand on the structural features and magnetic behavior of the diradicals was observed. The rigid conjugated ligand framework is proposed to allow for this electronic communication. Further research towards using the dinucleating framework as a reservoir to support multielectron small molecule activation are in progress.

\section{Acknowledgements}

This research was funded by the European Research Council (ERC) through Starting Grant EuReCat (27097) to J.I.v.d.V. We thank Prof. Dr. Franc Meyer for generous access to the SQUID magnetometer and Prof. Dr. Joost N. H. Reek for valuable support and scientific discussions. F.H. thanks the University of Reading for the support of the Reading Spectroelectrochemistry laboratory (Project D14-15).

Keywords: mixed valence $\cdot$ dinucleating ligand $\cdot$ redox-active ligand $\cdot$ palladium $\bullet$ intervalence charge transfer

[1] a) K. Prassides, Mixed Valency Systems-Applications in Chemistry, Physics and Biology, Kluwer Academic Publishers, Dordrecht, 1991; b) W. Kaim, G. K. Lahiri, Angew. Chem. Int. Ed. 2007, 46, 1778; c) P. Day, N. S. Husk, R. J. H. Clark, Phil. Trans. Royal Soc. A 2008, 366, 5; d) E. I. Solomon, X. Xie, A. Dey, Chem. Soc. Rev. 2008, 37, 623; e) S. D. Glover, J. C. Goeltz, B. J. Lear, C. P. Kubiak, Eur. J. Inorg. Chem. 2009, 585; f) M. Parthey, M. Kaupp, Chem. Soc. Rev. 2014, 43, 5067

[2] M. B. Robin, P. Day, Adv. Inorg. Chem. Radiochem. 1967, 9, 247.

[3] Synthesized from an iron salt and hydrogen cyanide: a) P.-J. Macquer, Mémoires de l'Académie royale des Sciences année, 1752, 60; b) K. R. Dunbar, R. A. Heintz, Progr. Inorg. Chem. 1997, 45, 283.

[4] a) C. Creutz, H. Taube, J. Am. Chem. Soc. 1969, 91, 3988; b) C. Creutz, H. Taube, J. Am. Chem. Soc. 1973, 95, 1086.

[5] a) D. O. Cowan, C. LeVanda, J. Park, F. Kaufman, Acc. Chem. Res. 1973, 6, 1; b) C. Levanda, K. Bechgaard, D. O. Cowan, M. D Rausch, J. Am. Chem. Soc. 1977, 99, 2964.

[6] K. D. Demadis, C. M. Hartshorn, T. J. Meyer, Chem. Rev. 2001, 101, 2655.

[7] a) J. Hankache, O. S. Wenger, Chem. Rev. 2011, 111, 5138; b) A. Heckmann, C. Lambert, Angew. Chem. Int. Ed. 2012, 51, 326.

[8] G. Qian, Z. Y. Wang, Chem. Asian J. 2010, 5, 1006.
[9] a) S. Luo, E. Zhang, Y. Su, T. Cheng, C. Shi, Biomaterials 2011, 32, 7127; b) J. O. Escobedo, O. Rusin, S. Lim, R. M. Strongin, Curr. Opin. Chem. Biol. 2010, 14, 64.

[10] Selected examples: a) T. Kundu, B. Sarkar, T. K. Mondal, S. M. Mobin, F. A. Urbanos, J. Fiedler, R. Jiménez-Aparicio, W. Kaim, G. K. Lahiri, Inorg. Chem. 2011, 50, 4753; b) M. M. Bittner, D. Kraus, S. V. Lindeman, C. V. Popescu, A. T. Fiedler, Chem. Eur. J. 2013, 19, 9686; c) N. Deibel, D. Schweinfurth, S. Hohloch, M. Delor, I. V. Sazanovich, M. Towrie, J. A. Weinstein, B. Sarkar, Inorg. Chem. 2014, 53, 1021; d) A. K. Das, B. Sarkar, J. Fiedler, S. Zális, I. Hartenbach, S. Strobel, G. K. Lahiri, W. Kaim, J. Am. Chem. Soc. 2009, 131, 8895; e) D. Herebian, K. E. Wieghardt, F. Neese, J. Am. Chem. Soc. 2003, 125, 10997; f) K. Chlopek, E. Bothe, F. Neese, T. Weyhermüller, K. Wieghardt, Inorg. Chem. 2006, 45, 6298; g) S. Fuse, H. Tago, M. M. Matiani, Y. Wada, T. Takahashi, ACS Comb. Sci. 2012, 14, 545.

[11] a) D. L. J. Broere, R. Plessius, J. I. van der Vlugt, Chem. Soc. Rev. 2015, 44, 6886; b) J. I. van der Vlugt, Eur. J. Inorg. Chem. 2012 363; c) V. Lyaskovskyy, B. de Bruin, ACS Catal. 2012, 2, 270; d) W. I. Dzik, J. I. van der Vlugt, J. N. H. Reek, B. de Bruin, Angew. Chem., Int. Ed. 2011, 50, 3356; e) W. Kaim, Inorg. Chem. 2011, 50, 9752; f) P. J. Chirik, K. Wieghardt, Science 2010, 327, 794; g) J. L. Wong, R. H. Sánchez, J. C. Logan, R. A. Zarkesh, J. Ziller, A. F. Heyduk, Chem. Sci. 2013, 4, 1906; h) T. W. Myers, L. A. Berben, Chem. Commun. 2013, 49, 4175; i) A. L. Smith, K. I. Hardcastle, J. D. Soper, J. Am. Chem. Soc. 2010, 132, 14358; j) K. J. Sylvester, P. J. Chirik, J. Am. Chem. Soc. 2009, 131, 8772; k) M. Königsmann, N. Donati, D. Stein, H. Schönberg, J. Harmer, A. Sreekanth, H. Grützmacher, Angew. Chem. Int. Ed. 2007, 46, 3567.

[12] a) Y.-Y. Zhou, D. R. Hartline, T. J. Steiman, P. E. Fanwick, C. Uyeda, Inorg. Chem. 2014, 53, 11770; b) H. Isobe, K. Tanaka, J.R. Shen, K. Yamaguchi, Inorg. Chem. 2014, 53, 3973; c) T. Wada, K. Tsuge, K. Tanaka, Inorg. Chem. 2001, 40, 329; d) D. Wang, S. V. Lindeman, A. T. Fiedler, Inorg. Chem. 2015, 54, 8744; e) S. Lindsay, S. K. Lo, O. R. Maquire, E. Bill, M. R. Probert, S. Sproules, C. R. Hess, Inorg. Chem. 2013, 52, 898; f) T. J. Dunn, L. Chiang, C. F. Ramogida, K. Hazin, M. I. Webb, M. J. Katz, T. Storr, Chem. Eur. J. 2013, 19, 9606; g) N. Deibel, S. Hohloch, D. Schweinfurth, F. Weisser, A. Grupp, B. Sarkar, Chem. Eur. J. 2014, 20, 15178.

[13] a) W. Kaim, B. Schwederski, Coord. Chem. Rev. 2010, 254, 1580; b) S. Sproules, K. Wieghardt, Coord. Chem. Rev. 2010, 254, 1358; c) C. G. Pierpont, C. W. Lange, Prog. Inorg. Chem. 1994, 41, 331; d) C. G. Pierpont R. M. Buchanan, Coord. Chem. Rev. 1981, 38, 45-87.

[14] a) C. G. Pierpont, Inorg. Chem. 2011, 50, 9766; b) R. M. Buchanan, J. Claflin, C. G. Pierpont, Inorg. Chem. 1983, 22, 2552; c) S. Kokatam, T. Weyhermüller, E. Bothe, P. Chaudhuri, K. Wieghardt, Inorg. Chem. 2005, 44, 3709; d) T. Storr, E. C. Wasinger, R. C. Pratt, T. D. P Stack, Angew. Chem. Int. Ed. 2007, 46, 5198; e) C C. Lu, S. DeBeer George, T. Weyhermüller, E. Bill, E. Bothe, K. Wieghardt, Angew. Chem. Int. Ed. 2008, 47, 6384; f) C. C. Lu, E. Bill, T. Weyhermüller, E. Bothe, K. Wieghardt, J. Am. Chem. Soc. 2008, 130, 3181; g) M. M. Khusniyarov, T. Weyhermüller, E. Bill, K. Wieghardt, J. Am. Chem. Soc. 2009, 131, 1208; h) T. Kurahashi, H. Fujii, J. Am. Chem. Soc. 2011, 133, 8307 ; i) L. Chiang, A. Kochem, O. Jarjayes, T. J. Dunn, H. Vezin, M. Sakaguchi, T. Ogura, M. Orio, Y. Shimazaki, F. Thomas, T. Storr, Chem. Eur. J. 2012, 18, 14117; j) L. Lecarme, L. Chiang, C. Philouze, O. Jarjayes, T. Storr, F. Thomas, Eur. J. Inorg. Chem. 2014, 3479;

[15] Recent review: a) B. Sarkar, D. Schweinfurth, N. Deibel, F Weisser, Coord. Chem. Rev. 2015, 293-294, 250-262. Elegant examples: b) A. Dei, D. Gatteschi, L. Pardi, Inorg. Chem. 1990, 29, 1442; c) B. Sarkar, S. Patra, J. Fiedler, R. B. Sunoj, D. Janardanan, G. K. Lahiri, W. Kaim, J. Am. Chem. Soc. 2008, 130, 3532; d) S. Ghumaan, 
B. Sarkar, S. Maji, V. G. Puranik, J. Fiedler, F. A. Urbanos, R. J.-Aparicio, W. Kaim and G. K. Lahiri, Chem. Eur. J. 2008, 14, 10816 e) S.R. Oakley, G. Nawn, K.M. Waldie, T.D. Maclnnis, B.O. Patrick, R.G. Hicks, Chem. Commun. 2010, 46, 6753; f) T. Kundu, B. Sarkar, T. K. Mondal, S. M. Mobin, F. A. Urbanos, J. Fiedler, R. J.-Aparicio, W. Kaim, G. K. Lahiri, Inorg. Chem. 2011, 50, 4753; g) G. Nawn, K.M. Waldie, S.R. Oakley, B.D. Peters, D. Mandel, B.O. Patrick, R. McDonald, R.G. Hicks, Inorg Chem. 2011, 50, 9826; h) S. D. J. McKinnon, B. O. Patrick, A. B. P. Lever, R. G. Hicks, Inorg. Chem. 2013, 52, 8053; i) D. Schweinfurth, Y. Rechkemmer, S. Hohloch, N Deibel, I. Peremykin, J. Fiedler, R. Marx, P. Neugebauer, J. van Slageren, B. Sarkar, Chem. Eur. J. 2014, 20, 3475; j) P. Mondal, M. Chatterjee, A. Paretzki, K. Beyer, W. Kaim and G. K. Lahiri, Inorg Chem. 2016, 55, 3105

[16] A. Dei, D. Gatteschi, C. Sangregorio, L. Sorace, M. G. F. Vaz, Inorg Chem. 2003, 42, 1701

[17] D. L. J. Broere, B. de Bruin, J. N. H. Reek, M. Lutz, S. Dechert, J. I. van der Vlugt, J. Am. Chem. Soc. 2014, 136, 11574.

[18] D. L. J. Broere, L. L. Metz, B. de Bruin, J. N. H. Reek, M. A Siegler, J. I. van der Vlugt, Angew. Chem. Int. Ed. 2015, 54, 1516.

[19] D. L. J. Broere, S. Demeshko, B. de Bruin, E. A. Pidko, J. N. H. Reek, M. A. Siegler, M. Lutz, J. I. van der Vlugt, Chem. Eur. J. 2015, 21, 5879

[20] M. Abe, Chem. Rev. 2013, 113, 7011.

[21] a) C. Mukherjee, T. Weyhermüller, E. Bothe, P. Chaudhuri, Inorg Chem. 2008, 47, 2740; b) C. Mukherjee, T. Weyhermüller, E. Bothe, E. Rentschler, P. Chaudhuri, Inorg. Chem. 2007, 46, 9895; c) P. Chaudhuri, M. Hess, J. Mu, K. Hildenbrand, E. Bill, K. Wieghardt, J. Am. Chem. Soc. 1999, 121, 9599.
[22] Initial attempts to coordinate $\mathbf{L}^{\mathrm{H} 4}$ as a dinucleating ligand to palladium resulted in the formation of a mixture of palladium complexes. See the ESI for more details.

[23] One example with Ir: a) J. M. Fernández-Hernández, C.-H. Yang, J. I. Beltrán, V. Lemaur, F. Polo, R. Fröhlich, J. Cornil, L. de Cola, J. Am. Chem. Soc. 2011, 133, 10543. Recent examples with $\mathrm{Cu}$ and Ag: b) J. D. Crowley, P. H. Bandeen, Dalton Trans. 2010, 39, 612; P. M. Guha, H. Phan, J. S. Kinyon, W. S. Brotherton, K. Sreenath, J. T. Simmons, Z. Wang, R. J. Clark, N. S. Dalal, M. Shatruk, L. Zhu, Inorg. Chem. 2012, 51, 3465.

[24] S. N. Brown, Inorg. Chem. 2012, 51, 1251.

[25] This weak absorption is found at similar wavelengths for other mixed valent systems involving catecholate-semiquinone interconversions. However, in most cases the mixed valence relates to an $M^{n}-L^{n+1} \leftrightarrow M^{n+1}-L^{n}$ type interconversion due to the presence of a redox-active metal: a) D. Kiriya, H.-C. Chang, A. Kamata, S. Kitagawa, Dalton Trans. 2006, 1377; b) S. Goswami, A. Panja, R. J. Butcher, N. Shaikh, P. Banerjee, Inorg. Chim. Acta 2011, 370, 311; c) C. G. Pierpont, Inorg. Chem. 2011, 50, 9766; d) H.-C. Chang, S. Kitagawa, Angew. Chem. Int. Ed. 2002, 41, 130.

[26] Analysis of a Gaussian shaped IVCT absorption band would allow for quantification of the electronic coupling: a) P. F. Barbara, T. J. Meyer, M. Ratner, J. Phys. Chem. 1996, 100, 13148; b) B. S. Brunschwig, C. Creutz and N. Sutin, Chem. Soc. Rev. 2002, 31, $168 ;$ c) N. S. Hush, Prog. Inorg. Chem. 1967, 8, 391. Unfortunately, we were unable to quantify the amount of electronic coupling in $\mathbf{4}$ and $\mathbf{5}$, as both IVCT bands are far from being ideally Gaussian shaped. 


\section{Entry for the Table of Contents}

\section{FULL PAPER}

((Insert TOC Graphic here; max. width: $11.5 \mathrm{~cm}$; max. height: $2.5 \mathrm{~cm})$ )

In the context of developing strategies to access well-defined mixed valent complexes, we detail the synthesis, spectroscopy, redox-chemistry,

spectroelectrochemistry and solid-state structures of rare dinuclear mixed valent palladium monoradical species and their one-electron oxidized diradical analogues are described. These systems feature a novel dinucleating ligand with two redoxactive binding pockets, a triazole linker and $\mathrm{Cl}^{-}$or $1,1-\mathrm{N}_{3}{ }^{-}$as bridging co-ligand.

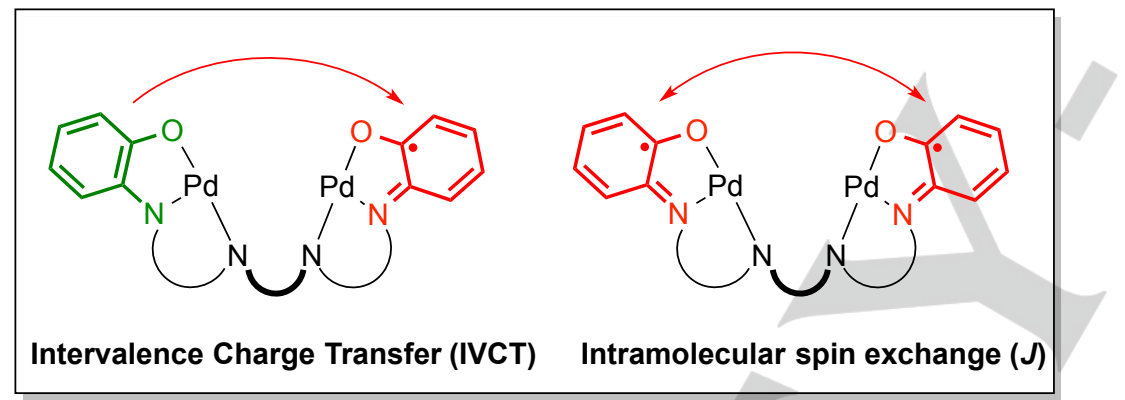

Daniël L. J. Broere, Raoul Plessius, Joanne Tory, Serhiy Demeshko, Bas de Bruin, Maxime A. Siegler, Frantisek Hartl and Jarl Ivar van der Vlugt*

Page No. - Page No.

Localized Mixed valence and RedoxActivity within a Triazole-Bridged

Dinucleating Ligand upon Coordination to Palladium 